\title{
BIOLOGICAL ACTIVITIES OF A MIXTURE OF BIOSURFACTANT FROM Bacillus subtilis AND ALKALINE
}

\section{LIPASE FROM Fusarium oxysporum}

\section{Cedenir Pereira de Quadros ${ }^{1 *}$; Marta Cristina Teixeira Duarte ${ }^{2}$; Gláucia Maria Pastore ${ }^{1}$}

${ }^{1}$ Departamento de Ciência de Alimentos, Faculdade de Engenharia de Alimentos, Universidade Estadual de Campinas, Campinas, SP, Brasil; ${ }^{2}$ Divisão de Microbiologia, Centro Pluridisciplinar de Pesquisas Químicas, Biológicas e Agrícolas, Universidade Estadual de Campinas, Campinas, SP, Brasil.

Submitted: May 13, 2009; Returned to authors for corrections: April 20, 2010; Approved: August 28, 2010.

\begin{abstract}
In this study, we investigate the antimicrobial effects of a mixture of a biosurfactant from Bacillus subtilis and an alkaline lipase from Fusarium oxysporum (AL/BS mix) on several types of microorganisms, as well as their abilities to remove Listeria innocua ATCC 33093 biofilm from stainless steel coupons. The AL/BS mix had a surface tension of around $30 \mathrm{mN} \cdot \mathrm{m}^{-1}$, indicating that the presence of alkaline lipase did not interfere in the surface activity properties of the tensoactive component. The antimicrobial activity of the AL/BS mix was determined by minimum inhibitory concentration (MIC) micro-assays. Among all the tested organisms, the presence of the mixture only affected the growth of B. subtilis CCT 2576, B. cereus ATCC 10876 and L. innocua. The most sensitive microorganism was B. cereus (MIC $0.013 \mathrm{mg} . \mathrm{mL}^{-1}$ ). In addition, the effect of the sanitizer against L. innocua attached to stainless steel coupons was determined by plate count after vortexing. The results showed that the presence of the AL/BS mix improved the removal of adhered cells relative to treatment done without the sanitizer, reducing the count of viable cells by $1.72 \log$ CFU. $\mathrm{cm}^{-2}$. However, there was no significant difference between the sanitizers tested and an SDS detergent standard $(p<0.05)$.
\end{abstract}

Key words: antimicrobial activity, Listeria innocua, microbial biofilm, minimum inhibitory concentration, stainless steel surface

\section{INTRODUCTION}

Microbial compounds that exhibit pronounced surface and emulsifying activities are classified as biosurfactants. They have primarily been used for environmental applications because of their diversity, environment-friendly nature, suitability for large-scale production and selectivity. Despite their potential and their biological origin, only a few studies have been carried out on their possible applications in biomedical fields. Some biosurfactants are suitable alternatives to synthetic medicines and antimicrobial agents, and they may be used as safe and effective therapeutic agents (21).

*Corresponding Author. Mailing address: Cidade Universitária "Zeferino Vaz", s/n, Departamento de Ciência de Alimentos - Lab. de Bioaromas, Rua Monteiro Lobato 80, Caixa postal: 6121, CEP: 13083-862, Campinas - SP, Brasil.; Tel.: +55 1935214090 Fax: + $551965213887 . ;$ E-mail: cdquadros@yahoo.com.br 
Many authors have already described antibiotic effects associated with biosurfactants. The antimicrobial properties of lichenysin A, a lipopeptide biosurfactant obtained from Bacillus licheniformis BAS50, were reported by Yakimov et al. (1995) (26). Recently, the effectiveness of a cyclic lipopeptide obtained from B. licheniformis 603 against diverse microorganisms has also been reported. It mainly inhibits the growth of Corynebacterium variabilis and Acinetobacter sp. (4). An isolated strain of Pseudomonas aeruginosa LB1 produces a biosurfactant with high antimicrobial activity against the bacteria B. subtilis, Staphylococcus aureus, Proteus vulgaris, Streptococcus faecalis and Pseudomonas aeruginosa, and also against the phytopathogenic fungi Penicillium sp., Alternaria sp., Gliocadium virens and Chaetonium globosum (5).

One report refers to surfactin, which is produced by Bacillus subtilis, as the first and most well-known member of the biosurfactant lipopeptides (2). The potential activities of surfactin include antibiotic and membrane effects (6), the ability to disturb lipid monolayers and affect biological membranes (12), altering the integrity of the lipid membrane with the formation of ion channels (7) and causing leakage and lysis of lipid membranes (14). The potential of some kinds of lipopeptides to alter surface tension or show antimicrobial activity is directly linked to their molecular structure $(5,11)$. Surfactin produced by B. subtilis LB5a in cassava wastewater has been reported to have antimicrobial activity, and it was found that all the bacteria tested were susceptible to lipopeptides. $P$. aeruginosa was the Gram-negative bacterium most sensitive to the product, and among the Gram-positive bacteria were Micrococcus luteus and B. cereus (17). Later, tests showed the antibacterial effect of surfactin from $B$. subtilis LB5a against many microorganisms, including the following: S. aureus, Salmonella choleraesuis, P. aeruginosa, Escherichia coli and B. cereus. For microorganisms such as E. faecium and M. luteus, the MIC values were lower than 1 $\mathrm{mg} \cdot \mathrm{mL}^{-1}(9)$.
A considerable number of bacteria are capable of attaching themselves to processing surfaces used in the food industry. These surfaces include stainless steel, glass, cast iron, polypropylene and formica. This attachment can start the processes of growth, adherence and biofilm formation. Microbial biofilms on contact surfaces can lead to contamination with undesirable microorganisms, resulting in food spoilage and transmission of disease (1). Listeria sp. is able to grow at refrigeration temperatures as low as $-1.5^{\circ} \mathrm{C}$, in environments with reduced water, in salt concentrations up to $30 \%$ and at $\mathrm{pH}$ values below 5.0. These characteristics contribute to its survival under conditions usually used to control the growth of pathogens in food (24). Thus, in food processing plants, it is often considered to be an important source of recontamination of foodstuffs and surfaces, especially when this microorganism is present as a biofilm (8). Many reports about the removal of microbial adhesions/biofilms from stainless steel surfaces using chemical treatments have been published $(1,8,23)$.

Despite the elucidation of various properties of surfactin in the 1960s, it was only in the 1980s that researchers devoted attention to finding an attractive alternative to synthetic surfactants, which may show marked toxicity and can cause significant environmental pollution (10).

The objective of this work was to investigate the effects of novel mixtures of the biosurfactant from Bacillus subtilis and alkaline lipase from $F$. oxysporum on the growth of various microorganisms in liquid medium using minimum inhibitory concentration (MIC) assays; furthermore, their efficacy at removing L. innocua biofilms from stainless steel surfaces was assessed.

\section{MATERIALS AND METHODS}

\section{Biosurfactant (BS) production}

B. subtilis from Biochemistry Laboratory Culture Collection (FEA, Unicamp, Brazil) was inoculated in cassava 
wastewater in a Mobile Pilot Plant Fermentor MP 80 (New Brunswick, Edison, NJ, USA). Fermentation was carried out according to the following parameters: temperature $35^{\circ} \mathrm{C}$, agitation $150 \mathrm{rpm}$ and $15 \mathrm{~L}^{-1} \mathrm{~h}^{-1}$ of aeration $(0.38 \mathrm{vvm})$ during the first $12 \mathrm{~h}$, followed by $25 \mathrm{~L}^{-1}{ }^{-1}(0.63 \mathrm{vvm})$ for the rest of the process. A sterile silicon tube was connected to the top of the bioreactor to recover the biosurfactant by withdrawing the foam produced during the process. After this, the liquefied foam collected was submitted to organic solvent treatment for biosurfactant extraction and purification steps (3).

\section{Determination of surface tension activity}

Measurement of the surface tension (ST) of biosurfactant solutions was carried out in a K-12 tensiometer (Krüss Processor Tensiometer, Hamburg, Germany) using the Whilhelmy plate method under the following conditions: plate dimensions of $40 \times 19.9 \times 0.1 \mathrm{~mm}$ and $10 \mathrm{~mL}$ of sample at room temperature, $\sim 20^{\circ} \mathrm{C}(3,17)$.

\section{Critical micelle dilution (CMD) measurement}

$\mathrm{CMD}^{-1}$ and $\mathrm{CMD}^{-2}$ were determined by measuring the surface tension of biosurfactant diluted in distilled water 10fold and 100-fold, respectively $(3,15)$.

\section{Alkaline lipase (AL) production}

F. oxysporum was cultivated for $96 \mathrm{~h}$ at $30^{\circ} \mathrm{C}$ on $\mathrm{YMA}$ medium containing (g. $\left.\mathrm{L}^{-1}\right)$ : peptone 5.0, glucose 10.0, malt extract 3.0, yeast extract 3.0, and agar 20.0. One $2-\mathrm{cm}^{2}$ piece from this culture was transferred to a $250 \mathrm{~mL}$-Erlenmeyer flask with $20 \mathrm{~mL}$ of liquid medium containing (g.L $\left.\mathrm{L}^{-1}\right)$ : olive oil 10.0, peptone 15.0, yeast extract 5.0, $\mathrm{K}_{2} \mathrm{HPO}_{4} 3.0$, and $\mathrm{MgSO}_{4} .7 \mathrm{H}_{2} \mathrm{O}$ $0.4, \mathrm{pH}$ 6.0. It was then homogenized with a T18 basic ultraturrax homogenizer (IKA ${ }^{\circledR}$ Works, Inc., Wilmington, USA) and incubated at $30^{\circ} \mathrm{C}, 160 \mathrm{rpm}$ for $24 \mathrm{~h}$. For lipase production, $1 \mathrm{~mL}$ of this pre-inoculum was transferred to $50 \mathrm{~mL}$ of fresh medium and incubated for an additional $96 \mathrm{~h}$ under the same conditions. The fermented medium was chilled, fractionated with ammonium sulfate and centrifuged at 9,500 $\times g(\mathrm{~J} 2-21$, Beckman Centrifuge, USA). Then, the freeze-dried extract was prepared after dialyzing against distilled water (20).

\section{Alkaline lipase/biosurfactant mixture (AL/BS mix) preparation}

The lyophilized lipase was dissolved in 50 mmol.L $\mathrm{L}^{-1}$ Tris$\mathrm{HCl} \mathrm{pH} 8.0$ buffer and filtered through an 0.22- $\mu \mathrm{m}$ membrane filter (Millex GV 33 mm, Millipore, Ireland). The powdered biosurfactant was dissolved in distilled water and autoclaved at $121^{\circ} \mathrm{C}$ for $15 \mathrm{~min}$. Mixtures (AL/BS mix) using both compounds at different concentrations were made under sterile conditions and had the surface activity measured as described above. These stock solutions were kept in sterile glass vials for the subsequent assays.

\section{Microorganism strains for antimicrobial assays}

The tests organisms Escherichia coli CCT 0547, Pseudomonas aeruginosa ATCC 13388, Bacillus subtilis CCT 2576, Staphylococcus aureus CCT 2740, Micrococcus luteus CCT 2692, Rhodococcus equii CCT 0541, Salmonella choleraesuis CCT 4296 and Candida albicans ATCC 10231 were obtained from Culture Collections of the Microbiology Laboratory at CPQBA (Unicamp, Brazil). Serratia marcescens CCT 0710 and Bacillus cereus ATCC 10876 were from André Tosello Foundation (Campinas, Brazil), and Listeria innocua ATCC 33090 was supplied by the Hygiene Laboratory at FEAUnicamp, Brazil.

\section{Inoculum preparation}

Microorganisms test strains were cultured in slant nutrient agar, brain heart infusion (BHI) or Sabouraud 4\% dextrose agar (all Merck ${ }^{\circledR}$ ) at $37{ }^{\circ} \mathrm{C}$ for $24 \mathrm{~h}$. One loop from each microorganism was transferred to $4 \mathrm{~mL}$ of $0.9 \%$ saline solution. Two milliliters were taken out for optical density adjustment using a spectrophotometer (UV-VIS Mini 1240, Shimadzu, Tokyo, Japan) to between 0.08 to $0.1 \mathrm{Abs}$ at $625 \mathrm{\eta m}$ 
(10 ${ }^{8}$ CFU.mL ${ }^{-1}$, according to McFarland turbidity standards). Afterwards, dilutions were made down to $10^{5} \mathrm{CFU} \cdot \mathrm{mL}^{-1}$ using Mueller-Hinton Broth medium (MHB) for bacteria, except for L. innocua for which BHI broth was used. In the case of $C$. albicans, the medium was RPMI 1640 (Cultilab).

\section{Minimum inhibitory concentration (MIC) tests}

MIC is the minimum concentration of an antimicrobial compound at which it inhibits the growth of microorganisms. One-hundred microliters of inoculum was inoculated into 96well microtiter plates containing serially diluted AL/BS mix in MHB, RPMI or BHI medium. The tests were performed simultaneously on negative controls (only medium), growth controls (medium + test organism) and sterility controls (medium + AL/BS mix). Plates were incubated under normal atmospheric conditions at $37^{\circ} \mathrm{C}$ for $24 \mathrm{~h}$. Twenty-five microliters of $0.1 \%$ 2,3,5-triphenyltetrazolium chloride $\left(\right.$ Merck $^{\circledR}$ ) was inoculated onto bacteria plates and incubated in the same conditions for $3 \mathrm{~h}$. The intensity of the red color indicates the growth of organism. For C. albicans, the color change of RPMI 1640 medium from pink to yellow indicates the growth of the yeast (25).

\section{Effect of the AL/BS mix on L. innocua biofilms}

The surface used was AISI 304 stainless steel with a total surface area of $1 \mathrm{~cm}^{2}$ vigorously washed by brushing. After three rinses in $100 \mathrm{~mL}$ of distilled water and cleaning by immersion in hexane, the coupons were placed into Petri dishes and autoclaved at $121^{\circ} \mathrm{C}$ for $15 \mathrm{~min}$ (18). The biofilm was prepared by submerging the sterile coupons into microtiter plates with $0.3 \mathrm{~mL}$ of previously prepared L. innocua inoculum and $2.7 \mathrm{~mL}$ of BHI medium at $10^{3} \mathrm{UFC}^{-\mathrm{ml}^{-1}}$ and incubating at $30^{\circ} \mathrm{C}$ for $24 \mathrm{~h}$. A control was carried out with $3 \mathrm{~mL}$ of culture medium (19). Then, the coupons were rinsed with $10 \mathrm{~mL}$ of sterile PBS (g.L $\mathrm{L}^{-1}$ of distilled water: $\mathrm{NaCl} 7.65$, anhydrous $\mathrm{Na}_{2} \mathrm{HPO}_{4}$ 0.724, $\mathrm{KH}_{2} \mathrm{PO}_{4} 0.21, \mathrm{pH}$ 7.4) to eliminate the unattached cells and placed into tubes containing $5 \mathrm{~mL}$ of 2 mg. $\mathrm{mL}^{-1}$ BS or AL/BS mix (2 mg.mL ${ }^{-1}$ each) for $10 \mathrm{~min}$ at 30 $\pm 2^{\circ} \mathrm{C}$. Then, the coupons were rinsed again with $10 \mathrm{~mL}$ of PBS for $1 \mathrm{~min}$ to eliminate the excess product, transferred to 5 $\mathrm{mL}$ of new PBS and vortexed for 2 min to release sessile cells from the coupons. To measure viable cells, $1 \mathrm{~mL}$ of suspension of sessile cells was serially diluted with peptone water and cultured on a BHI agar plate at $30^{\circ} \mathrm{C}$ for $24 \mathrm{~h}$ (16). A control group was performed using distilled water instead of the product. The results were expressed as the logarithm (log CFU. $\mathrm{cm}^{2}$ ) of the cells remaining on the coupons.

\section{Statistical analysis}

The mean value and respective standard error for each replicate were calculated by the software Microsoft ${ }^{\circledR}$ Excel 2000. The Tukey test was performed using the software SAS ${ }^{\circledR}$ System for Windows (SAS Institute Inc. Release 8.02 TS Level $02 \mathrm{M} 0$ ) and using a $p$-value of $5 \%$.

\section{RESULTS AND DISCUSSION}

\section{Biosurfactant stability}

Table 1 shows the effect of alkaline lipase on the surface activity of the AL/BS mix. The stability of the microbial surfactant can be seen in all the treatments with different concentrations of lipase, and it is confirmed by ST values around $30 \mathrm{mN} \cdot \mathrm{m}^{-1}$, in accordance with previously related data $(3,17)$.

Regardless of the lipase to biosurfactant ratio, the $\mathrm{CMD}^{-1}$ and $\mathrm{CMD}^{-2}$ values were the same as those of the control group with only BS present. The data reaffirm the fact that the biosurfactant from B. subtilis is resistant to treatment with enzymes, as was demonstrated in a previous study (9).

\section{Minimum inhibitory concentration (MIC)}

The results of antimicrobial activity assays in which BS and the AL/BS mix were tested against several microorganisms are shown in Table 2. Among the Gram-positive bacteria, only 
B. subtilis, B. cereus and L. innocua had their growth affected by the presence of the biosurfactant. In the case of $B$. subtilis, the presence of alkaline lipase decreased the MIC value relative to the biosurfactant alone from 1.75 to $0.75-1.0$ $\mathrm{mg} \cdot \mathrm{mL}^{-1}$. The most sensitive bacterium was $B$. cereus $(0.013$ mg. $\mathrm{mL}^{-1}$ ), but with the presence of lipase in the concentrations of $1: 1$ and $0.5: 1$, the MIC increased to $0.026 \mathrm{mg} \cdot \mathrm{mL}^{-1}$. The presence of lipase does not appear to have influenced the action of the biosurfactant on L. innocua (MIC $1.75-2.0 \mathrm{mg} \cdot \mathrm{mL}^{-1}$ ). These data show that the efficacy of the AL/BS mix treatment was significantly lower than that of standard antibiotics previously described in the literature. For example, the values for chloramphenicol against B. subtilis and B. cereus are 4.0 and 2.0 ug. $\mathrm{mL}^{-1}$, respectively (9). However, it must be considered that the purification grade of the biosurfactant and enzymatic extract are lower than the grade of a standard antibiotic. This fact probably contributed to higher MIC values of the AL/BS mixture. Gram-negative bacteria were not susceptible to treatment with BS or the AL/BS mix, nor was the yeast $C$. albicans.

Table 1. Effect of different alkaline lipase concentrations on biosurfactant surface activity.

\begin{tabular}{|c|c|c|c|c|}
\hline & Ratio & $\begin{array}{c}\mathbf{S T} \\
\left(\mathbf{m N} \cdot \mathbf{m}^{-1}\right)\end{array}$ & $\begin{array}{c}\text { CMD }^{-1} \\
\left(\mathrm{mN} \cdot \mathrm{m}^{-1}\right)\end{array}$ & $\begin{array}{c}\mathrm{CMD}^{-2} \\
\left(\mathrm{mN} \cdot \mathrm{m}^{-1}\right)\end{array}$ \\
\hline \multirow[t]{3}{*}{ Control } & ----- & 30.51 & 31.90 & 38.91 \\
\hline & $4: 1$ & 29.85 & 31.42 & 38.31 \\
\hline & $2: 1$ & 29.76 & 31.62 & 37.54 \\
\hline \multirow[t]{3}{*}{ AL/BS mix } & $1: 1$ & 29.90 & 31.56 & 38.16 \\
\hline & $0.5: 1$ & 30.00 & 31.87 & 38.22 \\
\hline & $0.25: 1$ & 29.45 & 31.19 & 37.89 \\
\hline
\end{tabular}

Control: lipase-free assay, AL/BS mix: alkaline lipase from $F$. oxysporum 152B and biosurfactant from $B$. subtilis LB5a mixture. The BS concentration for ST (superficial tension) was $1 \mathrm{mg} \cdot \mathrm{mL}^{-1}$. The ST, CMD ${ }^{-1}$ and $\mathrm{CMD}^{-2}$ (critical micelle dilution) values have standard deviations from ten measurements $\leq 0.2$.

Table 2. Minimum inhibitory concentrations (MICs) of the AL/BS mix (mg.mL ${ }^{-1}$ )

\begin{tabular}{|c|c|c|c|c|c|c|}
\hline \multirow{2}{*}{ Microorganism } & \multirow{2}{*}{ BS } & \multicolumn{5}{|c|}{ AL/BS mixture } \\
\hline & & $4: 1$ & $2: 1$ & $1: 1$ & $0.5: 1$ & 0.25:1 \\
\hline \multicolumn{7}{|l|}{ Gram-negative Bacteria } \\
\hline E. coli & $*$ & $*$ & $*$ & $*$ & $*$ & $*$ \\
\hline S. marcescens & * & $*$ & $*$ & $*$ & $*$ & $*$ \\
\hline P. aeruginosa & $*$ & $*$ & $*$ & $*$ & $*$ & $*$ \\
\hline \multicolumn{7}{|l|}{ Gram-positive Bacteria } \\
\hline B. subtilis & 1.75 & 1.0 & 0.75 & 0.75 & 1.0 & 1.0 \\
\hline S. aureus & $*$ & $*$ & $*$ & $*$ & $*$ & $*$ \\
\hline M. luteus & $*$ & $*$ & $*$ & $*$ & $*$ & $*$ \\
\hline B. cereus & 0.013 & 0.013 & 0.013 & 0.026 & 0.026 & 0.013 \\
\hline S. choterasuis & $*$ & $*$ & $*$ & $*$ & $*$ & $*$ \\
\hline L. innocua & 2.0 & 2.0 & 2.0 & 1.75 & 2.0 & 1.75 \\
\hline R. equii & $*$ & $*$ & $*$ & $*$ & $*$ & $*$ \\
\hline \multicolumn{7}{|l|}{ Yeast } \\
\hline C. albicans & $*$ & $*$ & $*$ & $*$ & $*$ & $*$ \\
\hline
\end{tabular}

(*) means > $5.0 \mathrm{mg} \cdot \mathrm{mL}^{-1}$ of biosurfactant. (x:y) means the ratio between alkaline lipase and biosurfactant. BS: biosurfactant from $B$. subtilis LB5a, AL/BS mix: alkaline lipase from $F$. oxysporum $152 \mathrm{~B}$ and biosurfactant mixture. 
The biological properties of lipopeptides have been widely reported, and since the 1960s biosurfactant activities have also been reported (2). The antibiotic activities of surfactin (Sigma) and lichenysin A from B. licheniformis BAS50 were compared and $15 \mu \mathrm{g}$ of both surfactants was used. The lipopeptide lichenysin A inhibited the growth of most of the tested bacteria on nutrient agar plates, but the inhibition was less than that observed with surfactin (26). Another study compared the antimicrobial activity of $B$. subtilis LB5a lipopeptide purified by adsorption chromatography with that of commercial surfactin. The purified surfactant from strain LB5a was more effective on its own than commercial surfactin $(200 \mu \mathrm{g})$ against all the tested microorganisms except for B. subtilis, which did not show susceptibility in the test. $P$. aeruginosa was the most sensitive bacterium, whereas E. coli, S. choleraesuis and $S$. marcescens were inhibited to a lesser degree. The lipopeptide also affected the growth of M. luteus and B. cereus (17). Next, the B. subtilis LB5a biosurfactant was tested against several microorganisms, including E. faecium and M. luteus, and these were inhibited at biosurfactant concentrations of 0.8 and 0.25 mg. $\mathrm{mL}^{-1}$, respectively (9). A biosurfactant isolated from a marine strain of Bacillus circulans was tested for antimicrobial action using the agar disc diffusion method against several pathogenic and semi-pathogenic organisms. Using solventextracted biosurfactant at a concentration of $1 \mathrm{mg} \cdot \mathrm{mL}^{-1}$, the authors observed the susceptibility of both Gram-positive and Gram-negative organisms and larger halos for M. flavus, B. pumilis and M. smegmatis (11).

Results have shown that ion-conducting pores can be formed by surfactin in artificial lipid membranes. Those results demonstrated that surfactin produces selective cationic channels in lipid bi-layer membranes, and they suggest that at higher salt concentrations, a dimer is involved in the channelforming process (22). Another study reports that given its amphiphilic character, it is presumed that surfactin's biological activity is a direct consequence of its interaction with its target membrane and the resulting alterations in the bi-layer's properties. More specifically, it seems clear that these properties are primarily related to its ability to alter membrane integrity by establishing strong interactions with phospholipid membrane constituents. Studies on the molecular mechanisms of surfactin showed that the compound has the ability to alter membrane permeability, leading to the loss of the internal vesicular contents through local destabilization of lipid packing, or "pore" formation (7).

There is good evidence that the membrane's barrier properties are damaged in areas where surfactin oligomers interact with the phospholipids at concentrations far below the onset of solubilization. This will cause structural fluctuations that may well be the primary mode of antibiotic action in addition to the other important biological effects of the lipopeptide. This type of peptide acts rapidly on membrane integrity rather than on other vital processes, and thus it might constitute the next generation of antibiotics (13).

\section{Effect of the AL/BS mix on the removal of L. innocua} biofilm from stainless steel

Table 3 shows the log of the number of L. innocua that remained on the stainless steel surface after $10 \mathrm{~min}$ of sanitizer exposure as determined by the plate count method after vortexing. Before the sanitizer solution treatment, the formation of L. innocua biofilms on the coupons was assessed. The number of L. innocua cells irreversibly attached was a function of incubation time, and it increased as the bacterial population increased in the BHI broth. After $24 \mathrm{~h}$, the population reached $6.34 \pm 0.10 \log$ CFU.cm ${ }^{-2}$ and did not increase any further (data not shown). The final $\mathrm{pH}$ of the inoculum used for biofilm formation was 6.0.

Significant differences $(p<0.05)$ were not observed between $\mathrm{BS}$ and the AL/BS mix in the treatment of adhered cells. Compared with the positive control used in the tests, it was observed that BS and the AL/BS mix were as effective as SDS at removing cells from stainless steel plates $(p<0.05)$, although smaller numbers of viable cells were obtained after 
the treatment with SDS. On average, the presence of sanitizer solution decreased the number of bacteria remaining on the plates by $0.97 \log$ (1.16 for SDS, 0.91 for BS and 0.84 for AL/BS mix log) relative to those without sanitizer treatment, indicating that the presence of alkaline lipase in the mixture did not influence the results.

Several other studies have shown that many cells adhered onto a surface are not released by vortexing. Those cells are considered to be irreversibly attached. In this study, it was observed that the number of irreversibly attached cells increased with contact time as the number of cells in the BHI broth increased (1).

Table 3. Number of L. іпnосиа remaining on stainless steel plates after treatment with various sanitizer solutions.

\begin{tabular}{|c|c|}
\hline Treatment & $\begin{array}{c}\text { Log } \\
\left(\text { CFU.cm }^{-2}\right)\end{array}$ \\
\hline Control & $6.74 \pm 0.24^{\mathrm{a}}$ \\
\hline Distilled water & $5.86 \pm 0.29^{b}$ \\
\hline $\mathrm{BS}$ & $4.95 \pm 0.43^{\mathrm{c}}$ \\
\hline AL/BS mix & $5.02 \pm 0.49^{\mathrm{c}}$ \\
\hline SDS & $4.70 \pm 0.40^{\mathrm{c}}$ \\
\hline
\end{tabular}

BS (biosurfactant from $B$. subtilis LB5a); AL/BS mix (alkaline lipase from $F$. oxysporum/biosurfactant mixture 1:1), SDS (sodium dodecyl sulfate $1 \%)$. Different letters indicate statistical differences $(\mathrm{p}<0.05)$

\section{ACKNOWLEDGMENTS}

The authors wish to thank the CNPq (Conselho Nacional de Desenvolvimento Científico e Tecnológico) for the financial support it provided, and they gratefully acknowledge Luciana Maria Ramires Esper M.Sc. for providing the stainless steel plates and the valuable explanations about the biofilm method.

\section{REFERENCES}

1. Andrade, N.J.; Bridgeman, T.A.; Zottola, E.A. (1998). Bactericidal activity of sanitizers against Enterococcus faecium attached to stainless steel as determined by plate count and impedance methods. J. Food Protect. 61 (7), 833-838.

2. Arima, K.; Kakinuma, A.; Tamura, G. (1968). Surfactin, a cristalline peptidelipid surfactant produced by Bacillus subtilis: isolation, characterization and its inhibition of fibrin clot formation. Biochim. Biophys. Res. Commun. 31 (3), 488-494.

3. Barros, F.F.C.; Ponezi, A.N.; Pastore, G.M. (2008). Production of biosurfactant by Bacillus subtilis LB5a on a pilot scale using cassava wastewater as substrate. J. Ind. Microbiol. Biotechnol. 35 (9), 10711078.

4. Batrakov, S.G.; Rodionova, T.A.; Esipov, S.E.; Polyakov, N.B.; Sheichenko, V.I.; Shekhovtsova, N.V.; Lukin, S.M.; Panikov, N.S.; Nikolaev, Y.A. (2003). A novel lipopetide, an inhibitor of bacterial adhesion, from the thermophilic and halotolerant subsurface Bacillus licheniformis strain 603. Biochim. Biophys. Acta 1634 (3), 107-115.

5. Benincasa, M.; Abalos, A.; Oliveira, I.; Manresa, A. (2004). Chemical structure, surface properties and biological activities of the biosurfactant produced by Pseudomonas aeruginosa LBI from soapstock. Antonie van Leeuwenhoek. 85 (1), 1-8.

6. Béven, L.; Wróblewski, H. (1997). Effect of natural amphipathic peptides on viability, membrane potential, cell shape and motility of mollicutes. Res. Microbiol. 148, 163-175.

7. Carrillo, C.; Teruel, J.A.; Aranda, F.J.; Ortiz, A. (2003). Molecular mechanism of membrane permeabilization by the peptide antibiotic surfactin. Biochim. Biophys. Acta. 1611 (1-2), 91-97.

8. Chavant, P.; Gaillard-Martinie, B.; Hébraud, M. (2004). Antimicrobial effects of sanitizers against planktonic and sessile Listeria monocytogenes cells according to the growth phase. FEMS Microbiol. Lett. 236 (2), 241-248.

9. Costa, G.A.N. (2005). Biotechnological production of surfactant of Bacillus subtilis in agro-industrial residue, characterization and applications. São Paulo, Brazil, 87p. (M.Sc. Dissertation. Faculty of Food Engineering. Unicamp).

10. Cserháti, T.; Forgács, E.; Oros, G. (2002). Biological activity and environmental impact of anionic surfactants. Environ. Int. 28 (5), 337 348.

11. Das, P.; Mukherjee, S.; Sen, R. (2008). Antimicrobial potential of a lipopeptide biosurfactant derived from a marine Bacillus circulans. J. Appl. Microbiol. 104 (6), 1675-1684.

12. Deleu, M.; Paquot, M.; Nylander, T. (2005). Fengycin interaction with lipid monolayers at the air-aqueous interface-implications for the effect of fengycin on biological membranes. J. Coll. Interf. Sci. 283 (2), 358365 .

13. Goldberg, J. (2001). Cyclic peptide antibiotics; self-assembly required. Trends Microbiol. 19 (10), 379.

14. Heerklotz, H.; Seelig, J. (2007). Leakage and lysis of lipid membranes induced by the lipopeptide surfactin. Eur. Biophys. J. 36 (4-5), 305-314. 
15. Makkar, R.S.; Cameotra, S.S. (1997). Biosurfactant production by a thermophilic Bacillus subtilis strain. J. Ind. Microbiol. Biotechnol. 18, $37-42$.

16. Miyano, N.; Oie, S.; Kamiya, A. (2003). Efficacy of disinfectants and hot water against biofilm cells of Burkholderia cepacia. Biol. Pharm. Bull. $26(5), 671-674$.

17. Nitschke, M.; Haddad, R.; Costa, G.N.; Gilioli, R.; Meurer, E.C.; Gatti, M.S.V.; Eberlin, M.N.; Höehr, N.F.; Pastore, G.M. (2004). Structural characterization and biological properties of a lipopeptide surfactant produced by Bacillus subtilis on cassava wastewater medium. Food Sci. Biotechnol. 13 (5), 591-596.

18. Parizzi, S.Q.F.; Andrade, N.J.; Silva, C.A.S.; Soares, N.F.F.; Silva, E.A.M. (2004). Bacterial adherence to different inert surfaces evaluated by epifluorescence microscopy and plate count method. Braz. Arch. Biol. Technol. 47 (1), 77-83.

19. Pizzolitto, E.L.; Pizzolitto, A.C.; Pozetti, G.L. (2001). Chemical and microbiological evaluation of the internal surfaces of aluminum tubes both unlined and lined with epoxy resin by means of the stereoscope and scanning electron microscope. Braz. J. Microbiol. 32 (4), 340-344.

20. Prazeres, J.N.; Cruz, J.A.B.; Pastore, G.M. (2006). Characterization of alkaline lipase from Fusarium oxisporum and the effect of different surfactants and detergents on the enzyme activity. Braz. J. Microbiol. 37
(4), 505-509.

21. Rodrigues, L.; Banat, I.M.; Teixeira, J.; Oliveira, R. (2006). Biosurfactants: potential applications in medicine. J. Antimicrob. Chemotherapy. 57 (4), 609-618.

22. Sheppard, J.D.; Jumarie, C.; Cooper, D.G.; Laprade, R. (1991). Ionic channels induced by surfactin in planar lipid bilayer membranes. Biochim. Biophys. Acta. 1064 (1), 13-23.

23. Somers, E.B.; Wong, A.C.L. (2004). Efficacy of two cleaning and sanitizing combinations on Listeria monocytogenes biofilms formed at low temperature on a variety of materials in the presence of ready-to-eat meat residue. J. Food Protection. 67 (10), 2218-2229.

24. Teixeira, P.; Lima, J.; Azeredo, J.; Oliveira, R. (2008). Adhesion of Listeria monocytogenes to materials commonly found in domestic kitchens. Int. J. Food Sci. Technol. 43 (7), 1239-1244.

25. Wikler, M.A. (2005). Methods for dilution for antimicrobial susceptibility tests for bacteria that grown aerobically. Clin. Laboratorial Standards Inst. - CLSI. M7-A6, 23 (2).

26. Yakimov, M.M.; Timmis, K.N.; Wray, V.; Fredrickson, H.L. (1995). Characterization of a new lipopeptide surfactant produced by thermotolerant and halotolerant subsurface Bacillus licheniformis BAS50. Appl. Environ. Microbiol. 61 (5), 1706-1713. 